\title{
Elogio de la frialdad. Sobre el Estado de la modernidad postrevolucionaria
}

\section{FÉLIX DUQUE}

Como queriendo desmentir, con su impresionante carácter de duda y perplejidad, la idea del círculo de círculos y la cerrazón del pensar (Abgeschlossenheit des Denkens), el último texto filosófico de Hegel, escrito justamente siete dias antes de su muerte bajo el poder del cólera -otra excitante parado$\mathrm{ja}-$, viene constituido por el prólogo a la segunda edición de la Logica del ser, es decir, del inicio del sistema de la entera filosofia (en la portada central de la nueva obra campea el título: System der objectiven Logik). El último párrafo de este prólogo encierra una confesión de impotencia: Hegel sabe que la escritura del relato (Vortrag) no está a la altura de la exposición (Darstellung) del concepto divino que se cierra diamantina, impenetrablemente sobre sí mismo y, por ello, se abre infinitamente en y como llanura de la naturaleza. Una disculpa se aventura: «en consideración a la magnitud de la tarea tuvo el autor que contentarse con lo que ha podido hacer, dadas las circunstancias de necesidad exterior, de inevitable dispersión a causa de la magnitud (mas también, grandeza) y pluralidad de aspectos (Grösse und Vielseitigkeit) de los intereses temporales, e incluso bajo la duda de si el tonante ruido del día (laute Lerm des Tages) y la ensordecedora charlataneria de la imaginación, que se vanagloria de limitarse a estar al día, dejarán todavía espacio a la participación en la desapasionada calma (an der leidenschaftlosen Stille) del conocimiento puramente pensanten. ${ }^{1}$
La disculpa se mueve en dos planos: el álimo, el del griterfo del día y la charlatanería de la imaginación, corresponde a algo patologico: una enfermedad o recaída del logos en los estadios más naturales ( $y$ por ende, impotentes ante el concepto) de la reacción clerical y política. La Prusia en la que muere el filósofo es bien distinta de aquella que a finales de 1818 lo habra acogido, y que era tenida por él como sintesis encamada de los esfuerzos de la razón pura (el legado de Kant y Fichte) y de la razón práctica (la colisión, al principio violenta, entre los ideales de la Revolución francesa y el principio luterano del libre examen y del infinito valor de la subjetividad). Tras el asesinato de Kotzebue en 1819 y los Acuerdos de Karlsbad (Karlsbader Beschlitsse), firmados en el verano de ese mismo año, se ha desatado sobre Europa Central la tristemente célebre "Persecucion de demagogos" (Demagogenverfolgung), espoleada por la Santa Alianza: la Restauración se vuelve contra intelectuales liberales y progresistas. Comienza la sangría interior de Alemania, o el exilio hacia Francia, que al menos dispone de la Charte constitucional de Luis XVIII (1814).

En este clima crispado surgen banderías radicalmente opuestas que desgarran el tejido de la intelligentzia alemana. Por una parte, el movimiento liberal y progresista del Premarzo (Vormärz), es decir, de preparación para la Revolución de 1848. En él se encuadran hombres como Heinrich Heine, Ludwig Börne o Karl Gutzkow -o con 
radicalización meteorica, Georg Büchner-. Es la Junges Deutschland, que evita paradojicamente la utilización del término deutsch, copado por la clericanalla, y que en un Ludolf Wienbarg sueña todavia con un "nuevo helenismo europeos (neuen europäischen Griechentum) ${ }^{2}$ y se baña en un deismo ilustrado garante de una afrancesada "fraternidad de todos los hombres" (Bruderschaft aller Menschen); y contra la Santa Alianza proclama Heine el advenimiento de «la gran liga de pueblos, la Santa Alianza de las naciones» (das grösse Völkerbündnis, die heilige Allianz der Nationen). ${ }^{3}$ Sin embargo, el movimiento está infectado de aquello mismo que ataca: sus principios son abstractos y bienintencionados, carentes de fuerza y profundidad analítica, con la excepción quizá de Heine $y$, desde luego, de Georg Büchner, para quien la diferencia entre potentados y desheredados es el "único elemento revolucionario que hay en el mundon. ${ }^{4}$ En un conjunto desperdigado de países pero que, bajo la dirección de la Austria de Metternich, siguen siendo predominantemente agrarios, Ia conexión del hegelianismo con el saintsimonismo (como en Heine) hace que el movimiento entero se tiña de ensonaciones religiosas y patéticamente morales (un caso parecido sufrirá España años después con el krausismo). Estos románticos de izquierdas que se avergüenzan de su país caen en la prédica de nuevos evangelios de la carne. En Die Zerrisenen, de 1832, un Ungern-Sternberg vaticina: "Llegará un día en que todas las religiones, todos los filosofemas se hundan en el polvo y en que los hombres, curados de toda enfermedad y miseria, se bañarán de nuevo desnudos en las fuentes eternas del paraísom. ${ }^{5}$

Pero, por otra parte, el oscurantismo más reaccionario se ha adueñado de Alemania y Austria, en una liga for- midable en la que entran tardorrománticos como Ludwig Tiek, Jahn -padre de los Tumvereine, o Asociaciones Gimnásticas-, las Burschenschaften estudiantiles y el movimiento teutonico de los Christgermanen. Revistas poderosas como la Hallersche Evangelische Kirchenzeitung o su homónima de Berlín andan a la caza de estos Französlinge, pervertidos en su republicanismo y galomania. La deutsches Wesen se afirma, orgullosa, contra lo «occidental» (westich): la democracia, el liberalismo y lo Zivilisatorisch, en general. Una sola muestra puede bastar, aunque sea algo tardía. En el número de octubre de 1835 de la Stuttgarter Litteraturblatt, Wolfgang Menzel publica un artículo contra la Unmoralische Literatur, execrada como el burdel (Bordell) en el que se celebra un nuevo y sacrilego oficio divino. Las reminiscencias bíblicas y "satánicas" son evidentes: "Quiero -dice Menzel- pisar la cabeza de la serpiente, que se caliente en los excrementos de la lujuria». Y termina: "Mientras yo viva, vergüenzas [Schändlichkeiten] de ese tipo, que deshonran [entweihen] la literatura alemana, no quedarán impunes":

Son las encontradas corrientes de un liberalismo soñador, que suspira por una nueva exportación de la Revolución francesa para regenerar por el fuego y la sangre la inerme Alemania, y de un oscurantismo beligerante y rabioso, las que encuentra en su camino la nave hegeliana, en la que se cumplen las palabras de Petrarca: «-Povera e nuda vai, Filosofia - / dice la turba al vil guadagno intesa ${ }^{7}$

Tal es la laute Lerm der Zeit, que impide la retirada del espiritu hacia el interior de sí mismo. Mas este griterio es la espuma de los dras. Una razón más profunda lo ha promovido, una razón que exige ser explicada filosoficamente: la Revolución francesa de julio de 
1830, la Revolución de Les Trois Glorieuses, y sus secuelas en los movimientos de liberación nacional en Belgica y Polonia. Éste es el plano fundamental. Recordemos que Hegel, en el Prólogo a la nueva edición de la Seirslehre (prologo, por lo demás, que habria de haberse extendido a la entera Logica, es decir al sistema que da razon de todo lo real), habia establecido un significativo paralelismo entre la magnitud de la tarea (Grösse der Aufgabe) y la magnitud y pluralidad de aspectos (Grösse und Vielseitigkeit) de los intereses temporales, los cuales conllevan una inevitable dispersión. Pero, ¿por qué es esta dispersión inevitable? La lógica y, por extension, la filosofía en su integridad no puede pasar al lado de los acontecimientos, refugiándose cobardemente en la calma del pensar puro. $\mathrm{Y}$ no lo puede porque el pensar piensa lo otro de la razón: la necesidad exterior. No hay hiato platonizante en Hegel. La filosofía es "su propio tiempo, comprehendido en pensamientos" (ihre Zeit in Gedanken erfasst), de acuerdo al conocido aforismo de otro gran próloga: el que abre la $\mathrm{Fi}$ losofía del Derecho escrita en $1820{ }^{8}$

Sin embargo, la caída de los Borbones en Francia, la separación de la católica Belgica de los Palses Bajos, dominados por la protestante Holanda, $y$ los levantamientos - no menos católicos y piadosos - de Polonia contra el yugo zarista, amenazan con hacer añicos el entero sistema hegeliano, y muy especialmente su filosofia de la historia, trabajosamente reformulada desde los tiempos de Jena para poder hacer conciliables la exportación napoleónica de los principios de la Gran Revolución, contrarrestados por unas guerras de liberación (Befreiungskriege) en las que Alemania acaba por infectarse venturosamente de los gérmenes que ella misma combate, por una parte, y los principios luteranos, laicamente vertidos en la institución del matrimonio en la consecución de riquezas mediante el trabajo burgués, y en la honradez en los contratos y el respeto a la ley, por otra. Ese travestismo del luteranismo (por usar el expresivo término italiano) habría dado al traste con los votos católicos de la castidad, la pobreza y la obediencia, vencidos por la irrupción de la ueticidad en la sociedad civil" (Sittlichkeit in der burgerlichen Gesellschaft). ${ }^{9}$

Pero los acontecimientos internacionales de 1830 parecian trastocar por entero este orden de cosas. En principio, Les trois Glorieuses francesas parecen más fácilmente asimilables por la filosoffa hegeliana. Al fin, la Francia de Carlos $\mathrm{X}$ vivía en su carne la confrontación irresuelta entre una Constitución (la Charte) de orientación liberal y la presencia cada vez más acentuada de un oscurantismo feroz, que restauraba los viejos privilegios y establecía una férrea censura de prensa. Tras la caída del gobierno reaccionario de Villele en 1827 y la elevación a la presidencia de la Cámara de Royer-Collard, jefe del ala liberal-moderada y profesor de filosofía, la posición de Hegel no puede ser más clara. En su carta a Victor Cousin del 3 de marzo de 1828, Hegel se alegra de esas *victoires, dont chaque jour de poste nous annonce une nouvelle» y se congratula de ver a un profesor de filosofia a la cabeza de una Cámara, "dont la composition a si furieusement trompé les gens en place», Y aunque reste mucho por hacer: «il m'a semblé qu'on ait gagné l'essentiel, c'est d'avoir produit dans les quartiers les plus hautes la conviction que la marche qu'on avait prise jusque-là ne puisse se continuer ni reprendre». Mas lo que brilla con fuerza en este importante escrito es la felicitación a Cousin por haber demorado sus vaca- 
ciones en el mar, uet que vous avez préféré à leur brute rugissement d'être près de la musique du tocsin de l'energie liberale, dont Paris, toute la France et l'Europe retentits. ${ }^{\text {to }}$ Es la energía liberal del gabinete Martignac la que celebra aquí Hegel, con la confianza de su irradiación por toda Europa. A través de hombres como von Henning, Gans y sobre todo el hugonote Michelet, Hegel se propone en efecto, desde los Jahrbucher für wissenschaftiche Kritik, una política cultural de fomento reciproco de ideas entre Francia y Alemania como bastión de la reforma progresista frente a la Restauración de Metternich. Mas esa alegría liberal durará poco: en 1829, Carlos $X$-que ya se había hecho coronar en Reims a la antigua usanza, para reivindicar el origen divino del poder real- instaura un gobierno presidido por Polignac, jefe de la Congrégation, una secta ligada a los jesuitas. Las garantías constitucionales quedan sin efecto y la Charte es anulada. El 29 de julio de 1830, Carlos $\mathrm{X}$ deja sin vigor las Ordenances.

Se trata de un verdadero golpe de Estado, gestado en el interior del propio pader, al que contesta el pueblo de París lanzándose a la calle alzando barricadas durante tres días. Los ejércitos enviados para sofocar la insurrección se pasan en gran parte a los sublevados y el viejo héroe La Fayette, testigo de las dos grandes revoluciones, la americana y la francesa, se encarga hábilmente de transformar el motín en la instauración de la casa de Orléans: comienza el reinado de Luis Felipe, el rey burgués. Es Heinrich Heine el que, muy significativamente, define a su maestro como el "Orleans de la filosofias," estableciendo un claro paralelo con los esfuerzos de Hegel por lograr una reforma liberal en el pensamiento y los de La Fayette, que ha logrado controlar a los exaltados politische Romantiker que querían repetir un "tiempo de horrible memoria" y presagiaban eun nuevo drama, en el cual habria corrido más sangre y donde sobre todo el verdugo habria tenido que hacers.12 El espectro del Comite du salut publique resulta pues amenazador aun para Heine.

Lo que a Hegel preocupa fundamentalmente, sin embargo, es el hecho del levantamiento del pueblo. Esa Revolución no ha sido dirígida por un gran hombre ni por una élite, sino que ha sido realizada por el Póbel, el cual no encontraba cabida en el Estado de derecho que el filosofo quería ayudar a instaurar. Por contra, el carácter espontáneo de esta revuelta popular sería ditirámbicamente elogiado como «mesianismo del pueblow por Jules Michelet en su introducción de 1869 a su Histoire Universelle. Ese Juillet éternel, escribe Michelet, ha consistido en "une révolution sans héros, sans noms propres; point d'individu en qui la gloire ait pu se localiser, La société a tout fait. Après la victoire on a cherché le héros, on a trouvé un peuple», Mas no debemos dejarnos engañar por estas declaraciones. Lo que se alaba aquí no es una victoria popular, sino la transfiguración imperialista de la Francia revolucionaria, el nacimiento de un chauvinismo a ultranza en el que Europa acabará desangrándose. Francia se arroga ahora la hegemonía mundial. Michelet continúa diciendo, en efecto: «Le monde moral eut son Verbe dans le Christianisme, fils de la Judée et de la Grece; la France expliquera le Verbe du monde social que nous voyons commencer»..$^{13} \mathrm{Y}$ Lamartine contribuirá a la creación de la funesta idea de las gesta Dei per francos en su Jocelyn de 1836:

Les temps, par Dieu même conduit, Passe, pour avancer, sur ce qu'il a détruit. 
Un Nouveau Christianisme, pues, como el predicado por Saint-Simon en 1825; solo que ahora el Cristo es la Francia personificada como Heiland, la tierra de la salvación. Antes - dice Michelet- hombres eminentes habian estudiado sus avatares históricos desde el punto de vista político: "Le premier, je la vis comme une âme et une personnew. ${ }^{14}$

Contra esta interesada deificación (detrás de ella estaban hombres como Thierry y Adolphe Thiers, el sanguinario represor de la Commune) se levanta Hegel, dado que tal chovinismo sirve paradojicamente para atizar por reacción movimientos hipernacionalistas en tierras alemanas, impidiendo ver asi, tras el manto hieratico de la sacralizada Nación, los intereses economicos que promueven esa exaltación. Parses como Brunsvick, Sajonia, Hannover (en verdad, protectorado inglés, centro de la reacción) o el Electorado de Hessen se habian apresurado a promulgar Constituciones, tras el ejemplo de la Julirevolution, en las que la letra mataba la posibilidad de un verdadero desarrollo progresista de las fuerzas de la economía y la cultura. Por eso, en la carta al editor Cotta del 29 de mayo de 1831, se mofa Hegel de ulas imitaciones de las supuestas liberalidades [Freiheitstümlichkeiten: un término peyorativo intraducible] francesas, hechas por principes alemanes [...] que empiezan a resultar molestas y gravosas para algunos gobiernos y ministerios? 15

Al filosofo no le incomoda el hecho de la Revolución; al contrario, esta ha puesto a la luz las contradicciones en Francia de la pretendida Restauración. Es imposible gobernar autoritariamente, tras la experiencia napole6nica: «el punto sobre el que se asienta este tiempos (der Standpunkt dieser Zeit) -se dice en el curso de invierno de 1830-31 sobre Filosofia del Derecho- consiste justamente en que "ya no tiene por válido aquello que se limita a descansar sobre la autoridad; las leyes se deben legitimar mediante el concepto. [...] En nuestros dias (heutigestags) es justamente el derecho divino el más refutado (Verworfenste) ". ${ }^{16}$

Es más: la irrupción de la libertad secular frente a la opresión catolica era clara señal, para Hegel, de que «los franceses [...] han dejado de hecho de pertenecer a la religión católica, pues ésta no puede conceder nada sino que, consecuentemente, exige en todo la absoluta sujeción a la Iglesian. ${ }^{17}$ De hecho, este pueblo habria conseguido refrendar, en 1830, la Gran Revolución de 1789. Tanto en ciencias como en historia, la regla de oro conseguida en efecto por Hegel es la de que la sola aparición de un fenómeno (valga la redundancia) no aclara si tras éste se esconde o no algo esencial. Es la repetición del mismo la que permite la elevación a fundamentos $\mathrm{y}$, de ahí, al concepto: "Una sola vez puede ser fácilmente considerada como si nada hubiera ocurrido, mientras que la segunda refrenda la primeras. ${ }^{18}$ Dos veces cayo Napoleón, dos veces han caído los Borbones. Toda Restauración parece pues imposible, por principio.

$\mathrm{Y}$ sin embargo, Karl Hegel nos informa respecto a la Julirevolution: «Mi padre vio en ella, aterrorizado, una catástrofe, que parecia hacer vacilar el seguro terreno del estado racional".19 ¿A que obedecia tal terror? En primer lugar, según creo, al miedo de una nueva exportación de la revolucion, lo que echaría por tierra la lenta colaboración que, al menos en el terreno cultural, se venia produciendo (baste pensar en figuras mediadoras como Cousin o KL. Michelet y, en un orden más "mundano", el gran Heine). En segundo lugar, existía el peligro cierto de 
una guerra general conducida contra Francia, aprovechando los tumultos de Polonia, según advierte Oken a Hegel en su carta de la primavera de $1831 . .^{20}$ La inquina contra lo francés habría llevado entonces a Alemania a una exacerbación reactiva de lo nacional (de hecho, pujante ya en los grupos teutónicos). Pero en tercer y fundamental lugar estaba el miedo de Hegel a una insurrección de la plebe, de ese residuo creciente que ni siquiera llegaba a Klasse (como era el caso de los jornaleros del campo y los obreros), y cuyo odio podía ser utilizado por arribistas de toda laya. Una ceremonia fúnebre en honor del duque de Berry habia sido obstaculizada en Paris, el 15 de febrero de 1831, por masas incontroladas que acabaron destruyendo el palacio episcopal. Hegel comenta: «Parece que la Garde Nationale haya tenido miedo del pueblo y permanecido pasiva; sólo después de que todo hubiera pasado ha intervenido éstaw ${ }^{21}$

¡Miedo del pueblo! O, más bien, miedo de que el pueblo (Volk), en Francia, se estuviera convirtiendo por la industrialización y la licuación de los viejos estamentos (abolidos ya, p.e., en Inglaterra) en plebe (Pöbel). Contra el fácil y demagógico recurso al pueblo (al pueblo recurriría también un Hitler en 1933), para Hegel la exacta definición de Volk es: «el que no sabe lo que quiere" (der nicht weiss, was er will).22 Justamente, caracteristica del gran hombre es la de que, en un momento supremo de decisión, éste sea capaz de dar expresión a una presentida necesidad del pueblo y ser reconocido por él (se trata del carisma weberiano). Mientras esta salvaje energía no sea canalizada, el pueblo, y más exactamente la plebe surgida por la desmesurada ansia de riqueza del estamento fabril y comercial burgués, constituirá en todo momento una amenaza absoluta de re- belion; ya no de revolución, sino de vuelta al estado natural. Pues lo distin. tivo de la plebe no es su pobreza, sino sus intenciones, a saber, el resentimiento: "A nadie le convierte en plebe la pobreza: la plebe resulta determinada por vez primera por la convicción, surgida mediante la pobreza, de la irritación (Empörung) interna contra los ricos, la sociedad, el gobierno, etc.m. ${ }^{23}$ La sociedad civil se ve, así, amenazada en sus propios cimientos. Y Hegel no se hace ninguna ilusion sobre una posible transfusión de los bienes culturales -aportados a través del estamento fabril- a ese Lumpenproletariat. Para él, Hombre se dice por vez primera cuando tanto la "personas del derecho abstracto como el «sujeto» de la moralidad han sido asumidos en el sistema burgués de las necesidades. ${ }^{24}$

$Y$ es aquir donde yo me siento obligado a elogiar la frialdad hegeliana (un triste elogio, si se quiere) a pesar de que Hegel, falto de todo mesianismo y de toda romántica utopla, no vea otra solución para la creciente plebe que la emigración y colonización o, en su defecto, la sarcástica "solución escocesa, a saber: abandonar a los pobres a su destino y encaminarlos a la mendicidad pública». ${ }^{25}$ Marx dijo una vez: "Se ha atacado de muchas maneras a Hegel por el desarrollo que hace de la moral. Pero el no ha hecho otra cosa que desarrollar la moral del estado moderno y del moderno derecho privado. Se ha querido separar más a la moral del estado, emancipandola de éste. ¿Qué se ha probado con ello? Que la separación del estado actual respecto a la moral es cosa moral, que la moral no es cosa del estado y que el estado es inmoral ${ }^{26}{ }^{26}$ Hegel no pretende adoctrinar ni ser edificante: no sueña con paraísos perdidos porque sabe que la historia del hombre comienza con la libertad y el trabajo: justamente, 
con lo anatematizado como pecado original y calda.

Al respecto, el Zusatz 3 del $\$ 24$ del Vorbegriff a la Logica de la Enciclopedia presenta una espléndida interpretación del mito de la calda. Ser hombre significa estar conscientemente desgarrado de su ser natural. Toda defensa de un presunto estado de naturaleza es una ofensa contra la libertad humana. La supuesta maldición de Dios, que el hombre deba trabajar con el sudor de su frente y la mujer parir con dolor, constituye la verdadera posición del hombre como hombre, frente a la bruta, inconsciente satisfaccion animal. Así, el trabajo es visto "al mismo tiempo y en el mismo sentido como resultado de la escisión y como superación de la misma. El animal se topa de inmediato con lo que precisa para satisfacer sus necesidades; el hombre en cambio se comporta respecto a los medios de satisfacción de sus necesidades como frente a lo por él producido y conformado (Gebildeten)n. ${ }^{27}$ En esta formacion (Bildung), el hombre mismo se va haciendo. El capítulo VI-B de la Fenomenologta: El esptritu alienado de si mismo: la formación, eleva a concepto esta historia, que parte de la atomización de la persona abstracta en el derecho romano frente a la vaciedad del único Señor del Mundo, El Imperator; pasa a través de la Ilustración, que convierte la esencia objetiva del mundo en util para la autoconciencia, y desemboca justamente en la libertad absoluta y el Terror de la Gran Revolución: una nueva, invertida disolución de la autoconciencia en átomos singulares frente a la vaciedad del Etre Supreme, que a partir de 1830 intelectuales como Michelet buscarán identificar -nuevos evangelistas- con la grandeur de la France. Que esa Bildung secular haya sido en vano es lo que teme ahora Hegel. La irrupción del proleta- riado no puede encajar en un esquema en el que se celebran los fastos de la burguesía, aunque Hegel tenga el genio y la audacia de apuntar al problema: «La importante cuestión del modo en que sea posible subvenir a la pobreza es un problema que mueve y atormenta especialmente a las sociedades modernas». ${ }^{28}$ Mas, ¿por qué especialmente (vorzuglich) a la modernidad? Ello se debe a que esta halla su rasgo distintivo y su timbre de gloria en la maquinización, esto es: en la separación reflexiva de la naturaleza de la que procede. Astucia de la razón: «La herramienta como tal se interpone entre el hombre y su aniquilacion material; pero no por ello pasa a ser su formalidad, sigue estando su actividad dirigida a algo muerto; precisamente su actividad consiste esencialmente en matarlo, arrancarlo de su contexto vivo y presentarlo como algo que aniquilar, como eso, muerto. En la MÁQuiNa el hombre supera incluso esta actividad formal suya y hace que aquélla trabaje enteramente para el ${ }^{2 .}{ }^{29}$ Pero esa astucia se torna inmediatamente en artimaña de la naturaleza misma: ucada artimaña que emplea contra la naturaleza, sin salir por eso de la propia singularidad, se venga de él mismo; cuanto más se la somete, tanto más le rebaja a él lo que saca de ellaw. ${ }^{30} \mathrm{La}$ naturaleza muerta se transfiere asi al trabajador mismo: éste queda maquinizado, incapaz de comprender el proceso que a su través se dispara. El resultado es meramente cuantitativo; ya no estamento (Stand), según la reflexión formativa de lo natural, sino mera clase (Klasse): trabajador al servicio del $\mathrm{Fa}$ brikantenstand. Mas la máquina llega a desplazar incluso al trabajador mismo: "La abstracción del producir hace que el trabajo sea cada vez más mecanico y, por ende, capaz al cabo de eliminar (wegtreten) al hombre y de hacer en- 
trar en su lugar a la máquina”." Los hombres desechados se convierten, entonces, en plebe. No animal ni hombre, sino desecho de la producción: un regreso a la naturaleza tras la homogeneización del trabajo.

Al fin, lo que la Revolución francesa ha llevado a efecto en lo político no es sino una extensión del reino moderno de la máquina, en el nivel industrial. En ambos casos, el peligro estriba en esa rebelión de la naturaleza desechada: furia de la destrucción, furia de la desaparición, formalismo de la modernidad.

La solución que Hegel propone es fragil, y el es el primero en ser consciente de ello. Mas al menos impide la confusión beata, e interesada, entre sociedad civil y Estado, paradojicamente compartida tanto por liberales como por restauracionistas. Los primeros, porque sueñan con un Estado veilleur de nuit, que se limite a dejar que los capitalistas manipulen el poder político directamente; los segundos, porque pretenden volver a un sistema patriarcal en el que sociedad, familia heril y Estado despótico fueran ilusoriamente una y la misma cosa. Hegel no media entre estos extremos, porque ambos son desvarios de la senda historicoconceptual trazada en la Fenomenologia y en las Lecciones sobre Filosofía de la Historia. Estos epifenomenos han de ser dejados, como la plebe, a su suerte (una tarea fascinante al respecto sería la de comprobar, con rigor filosófico, si la historia efectiva se ha vengado de Hegel o si, más bien, por debajo de las luchas decimonónicas entre liberales y conservadores, se ha ido gestando un destino ya previsto por Hegel: la sociedad administrada y la universalización del funcionariado). La propuesta hegeliana en cambio, que tomada en la terminología caduca por el empleada podría parecer anacrónica, sigue una vía estrictamente histórica, templada por la carga del pensamiento político de Kant y Fichte. Esta propuesta consiste en el establecimiento de una base sólida del Estado postrevolucionario: la constitución (Verfassung) y los estamentos (Stände). Ambos puntos están inextricablemente conjuntados, e intentan anudar los dos lados de la individualidad moderna, sin confundirlos: el bourgeois, que recibe reconocimiento de sí mismo en la sociedad civil a través de sus propiedades, y el citoyen, que ve reconocidos sus derechos políticos mediante su intervención activa en el Estado. La particularidad del primero se alza a universalidad en el mercado de cambio de valores; la del segundo se hace valer como volonté générale en la legislación, garante a su vez de la fiabilidad de los contratos (remisión legal, a través de la sociedad civil, de la esfera estatal al punto de partida: el derecho abstracto).

En 1794, y como cortafuego de las ideas revolucionarias francesas, se habia establecido en Prusia el Allgemeines Landrecht (Codigo Civil, si queremos). Por el, los viejos estados generales, cuya disfunción había engendrado la llama de la libertad, quedan profundamente transformados. Ahora, los estamentos son la expresión de la organización económica y por ende los determinantes de la definición jurídica del ciudadano. Decisiva al respecto es la instauración de un tercer estado, junto a la nobleza terrateniente (los Gutsbesitzer, los Junker de la Prusia Oriental) y el campesinado. La burguesía es definida solo de forma negativa, y "comprende a todos los habitantes del Estado que por nacimiento no pueden ser contados como pertenecientes a la nobleza ni al campesinadon. 37 thora se añade un tercer estamento, de funcionalidad decisiva, y justamente definido por su función: es el funcio- 
nariado (Beamtenstand). Verdadero terminus medius, mas no Mitte, surge naturalmente de los dos primeros Stände, pero es pagado y controlado por el Gobierno. Su función es contradictoria, mas en el sentido del entendimiento analítico: por un lado, expresa el control centralista sobre las estructuras periféricas del Estado; por otro, dada su formación (Bildung), es el portavoz de la conciencia ilustrada, que reclama la participación del ciudadano en el Estado, la posibilita y encauza. Así, la paradoja del funcionariado estriba en que, por su origen de camarilla o covachuela (según los castizos términos con que se fustigó a esta tecnocracia en la época de nuestro Carlos III), los funcionarios parecen reliquia muerta de la política absolutista fredericiana; pero por su preparación y cambio de funcionalidad, van a ser los fautores de las reformas de Stein y Hardenberg, de Scharnhorst y Gneisenau para el ejercito, y de las de Altenstein para la educación.

En el Oktoberedikt de 1807, Stein y Hardenberg dan los primeros pasos hacia la unidad alemana siguiendo el modelo smithiano de economía liberal. Se rompe la rigidez provincial de los antiguos estamentos, estableciendo una apertura aduanera general y se promueve, desde la actividad social, la unidad de gestión estatal. El eje de la transformación es el funcionariado. El proposito, convertir el Landstand (estamento regional) en Staatstand (estamento estatal), para propiciar desde arriba una Staatsbürgergesellschaft, en la que la nueva burguesía fomentada acabaria por hacer que se diluyeran, sin necesidad de convulsión revolucionaria, los antiguos estamentos de la nobleza y el campesinado. ¡Pero de propiciar esta disolución viene encargado un estamento que está fuera de las categorias económicas y ha sido forjado dentro de un reformismo de raiz absolutista! Esta operación sólo podría resultar dialécticamente viable si la misma capa que se quería crear -siguiendo el modelo inglés, mas sin caer en el aborrecido atomismo representativo- reflexionaba sobre si misma y ponía límites racionales a su acción: en una palabra, si el nuevo Fabrikantenstand, la burguesfa, se doblaba en la Korporation del Beamtenstand.

Mas ello es por principio imposible, si nos atenemos a la propia doctrina hegeliana. En efecto, la burguesia industrial tiene su locus logicus en la escision entre el mundo tal como es en sí y el mundo tal como aparece (en el nivel de la Lógica de la esencia), y en el juicio infinito (en el nivel de la Lógica del concepto). Ligada al trabajo, a la reflexión y al entendimiento, la burguesía se desgarra frenéticamente en sus tres modalidades: el artesanado (Handwerkstand), la industria (Fabrikantenstand) y el comercio (Handelstand). A través de ellas se transmuta lo particular en universal: la categoria ilustrada del $u$ so de la cosa se torna en la postrevolucionaria del cambio de mercancias. El honor y reconocimiento que ese estamento recibe es, así, universal, pero abstracto: el dinero. $\mathrm{Y}$ éste se acumula como Kapital para la elaboración en serie de mercancías multivalentes, y en fin -triunfo de la abstracción - para la producción de máquinas, es decir de engramas de universalidad. Ahora, la operación hegeliana parece ir de suyo: el funcionariado se originaria del estamento burgués, que ha llegado a la universalidad $\mathrm{y}$, como allgemeiner Stand (estamento o clase universal), cuidaria de los intereses generales (allgemein, también) del cuerpo social. ${ }^{33}$ Mas esta transferencia es falaz, porque la universalidad burguesa es abstracta, indefinida: su actividad incesante es la del infinito 
malo (por eso es en ella donde arraiga el formalismo kantiano del Sollen), y la universalidad que desciende del Estado habria de ser concreta. Nada garantiza pues la reflexion; al contrario, tenemos aquí una quaternio terminorum, no un silogismo. El término medio está roto: si el funcionariado se deja llevar por su origen, la burguesía, la diferencia entre sociedad civil y Estado tiende a borrarse, lo que lleva a la catástrofe revolucionaria de la disolución de ambos (ésta es la vía prevista por el socialismo, en sus diferentes facetas); mas si el funcionariado obedece a su destino y finalidad: el Estado, la sociedad se convierte en puro reflejo pasivo de la Verwaltung: sociedad administrada, triunfo de la razón tecnopolítica (ésta parece ser la vía seguida por el fenecido socialismo real). Los funcionarios se aplican entonces a sí mismos la función completa de representación de la sociedad civil en el Estado. Ellos son la opinión pública formada: ${ }^{34}$ el sustituto del pueblo, de esa temida clase universal futura. La hipocresía llegará al colmo cuando el funcionariado y el pueblo (Volk) sean interesada e ideologicamente presentados como idénticos, en las diversas modalidades de los fascismos (corporaciones como última transformación de los estamentos: sindicatos verticales). Para paliar este peligro, Hegel cae abiertamente en el otro extremo: "es mejor que quien tiene el poder tenga también propiedad privada y no una paga anual, que de esa manera le haria aparecer como funcionario del pueblo" (Beamte des Volkes). ${ }^{35}$ Sólo que entonces el presunto Staatsbeamter defenderá los intereses de la nobleza terrateniente, de la que proviene. En el fondo, se reproduce dentro del aparato estatal de la reforma prusiana la misma lucha revolucionaria entre nobleza y burguesía. Wilhelm von Humboldt, por ejemplo, teme -ya en 1819- que el centralismo burocrático acabe por borrar los estamentos en nombre de una sola clase universal (justo lo que Hardenberg, y con él Hegel, pretendian con la Reforma), o sea: "que sólo el funcionario cuente algo y que por eso todo el mundo tienda a acercarse a esta clase (Klasse, no Stand)".36 Claro que la alternativa por el propuesta: la autoformación (Selbstbildung) y autonomía de los estamentos, con separación plena del control del Estado, no hace sino repetir a nivel de grupos la solución aristocrático-liberal que el mismo Humboldt, de joven, reivindicaba en los años noventa para el individuo (olvidando que sólo el propietario puede formarse a su albedrío).

La paradoja será disuelta por la fuerza, de modo que puede decirse que la propuesta de Hegel, aunque no deje de ser un valiente signo de rcbelión frente a lo establecido, nace en 1820 xya muerta de las prensas) (por recordar aqui a Hume). El artículo 7 de las Karlsbader Beschlusse de 1819 va a entender la constitución de los estamentos regionales (landständische Verfassung) como vuelta pura y simple a los viejos estamentos, basados en el privilegio y en el derecho privado (abstracto, en Hegel). Y en 1923 se restaurarán los Provinzialstände que Stein habra abolido. Ahora, contra Hegel y todos los reformistas, "la propiedad de tierras (Grundeigentum) es condición para que haya carácter estamental (Standschaft), ${ }^{37}$

La idea hegeliana de un estado so. cial (Sozialstaat) se esfuma, asi; y lo más peligroso es que la Rechtsphilosophie, leida desde la nueva optica creada por la reacción oscurantista (sólo ligera y efímeramente paliada en 1848), dará pie con sus oscilaciones y concesiones a una interpretacion oscilante, también ella, entre el estado poli- 
cial y una ciencia de la administración (Verwaltungslehre): entre el nazismo (piénsese en un Carl Schmitt) y la sociedad administrada criticada -desde diferentes perspectivas- por Heidegger y los frankfurtianos.

Asi, bien puede decirse que la Filosofia del derecho hegeliana muestra una herida abierta en la constitución (Verfassung y Konstitution) de Alemania. El Teseo que debía unificar por la fuerza la nación dividida, ${ }^{38}$ el enérgico Ministerium del Württemberg, formado por Amtleute, y que habría de oponerse valientemente a los intentos de restauración de los viejos estamentos privilegiados ${ }^{39}$ la Korporation como segunda rafz ética del Estado (superando y asumiendo asi a la familia), ${ }^{40}$ todas estas propuestas del atormentado quehacer de Hegel con la política y, más exactamente, con el problema de salvar el hiato entre sociedad y Estado, entre burgués y ciudadano, han quedado siniestramente deformadas en Alemania, tras los crimenes nazis. Dejo en el aire la pregunta de si esa deformación no se está extendiendo ahora planetariamente, como barruntaba Heidegger.

Mas, paradojicamente, la frialdad con que Hegel se atreve a mirar al monstruo, también él fró, más allá de ditirambos ocasionales y exclamaciones éticas aquí y allá esparcidas por el análisis de la Sittlichkeit (exclamaciones que de poco valen, desde el momento en que la Moralität está ya asumida, absorbida en el Estado), cn su honradez al presentar problemas que no se dejan manipular (y menos dialecticamente) hacen que esos textos helados, pero transidos de las con- vulsiones que han irrumpido en nuestro siglo, sigan siendo más dignos de meditación que tantas propuestas edificantes provenientes de dos extremos abstractos, el liberalismo y el restauracionismo conservador: los únicos que hoy, por lo demás, parecen quedarnos.

Al fin, que esos problemas le resulten insolubles a Hegel no implica otra cosa para él sino la necesidad de progreso del sistema hacia el Espiritu Absoluto. El Estado es el Dios terrestre; es pues, como en Hobbes, el Dios mortal, un dios finito que vuelve a la naturaleza por el punto suspendido sobre la vertical de la coerción estatal: la voluntad del monarca. Un punto sobre la «ì, en efecto; mas ese punto está cortado, escindido de la vertical. De nuevo, un salto que es un regreso. Dice Hegel: «Pero por encima de todos está el gobierno, el Espíritu que se sabe esencia general y realidad general, el absoluto si mismon, 41

Sólo que esta prepotencia es fingida; el punto está designado por el puro azar de la naturaleza; el extravio, lo que está fuera de sí (Aussersichseyn), es lo que ha elegido y ungido a este absoluto Selbst. Otra más de las astucias de la naturaleza para evitar el suicidio de sus hijos predilectos:

Sueña el Rey que es Rey, y vive Con este engaño mandando, Disponiendo y gobemando; $Y$ este aplauso, que recibe Prestado, en el viento escribe $Y$ en cenizas le convierte La muerte: jdesdicha fuerte! ¡Que hay quien intente reinar, Viendo que ha de dispertar En el sueño de la muerte! ${ }^{4 z}$ 


\section{NOTAS}

1. Wissenschaft der Logik (en adelante, WdL); Gesammelte Werke (en adelante, GW). 21: 209-16.

2. En J. Hermand (ed.), Das Junge Deutschland. Texte und Dokumente, Stuttgart, 1966, p. 379.

3. Ibid., p. 384 .

4. Ibid., p. 385.

5. Ibid, p. 379.

6. Ibid, p. 388.

7. I Sonetti del Canzionere, Sonetto 7, Barcelona, 1981, p. 76 .

8. Grundlinien der Philosophie des Rechis... (en adelante, Rechtsphì.), Gans, reed, Berlín, H. Klemmer, 1981, p. 27.

9. Enzyklopddie der philosophischen Wissenschaften (en adelante, Enz); Werke (en adelante, W), Francfort, Suhrkamp, 1970, $\S 552,10$ : 358359.

10. Briefe von und an Hegel (en adelante, Br.). Hamburgo, ed. J. Hoffmeister, 1969 , 3: 222.

11. Samtliche Schriften (K. Briegleb, G. Hantzschel y K. Pörnbacher eds.), Múnich, 1969-1978, 2 : 656.

12, Ibid., 2: 659

13. Cit. por M. Milner, Le romantisme: 1,1820 1843, París, 1973, p. 95.

14. En Milner, loc. cit.

15. Bt, 3: 341 .

16. Vorlesungen uber Rechtsphilosophie (ed. K.H. Ilting), 4, vols., Stuttgart / Bad Camstatt, 1973 s., 4: 923-924.

17. Vorlesungen uber die Philosophie der Retigion, en $W ., 17: 243$.

18. Vorlesungen uber die Philosophie der Weltgeschichte, Leipzig, Ed. De G. Lasson, 1919-1920, p. 712 .

19. Dokumente zu Hegels Entwicklung (ed. J. Hoffmeister), Stuttgart, 1936, p. 415.

20. Br. 3: 338 .

21. Uber die englische Reformbill, en Berliner Schriften (ed. J. Hoffmeister), Hamburgo, 1956. p. 699 .
22. Rechtsphil., \& 301, A.

23. Ibid., $\$ 244, \mathrm{Z}$,

24. Rechtsphil., \$190, ed. cit, p. 228. Cf. mi *Indigencia de la necesidads, en VV.AA., Eticidad y estado en el idealismo alemán, Valencia, 1987, p. 133.

25. Rechtsphil., \$ 245, A.

26. Kritik des Hegelschen Statsrechis, MEW, Berlín, 1956, 1/313.

27. $W .8: 89$

28. Rechtsphit., \$244, Z.

29. Jenaer Systementwïfe, I. Geistesphilosophie (1803-1804), en GW, G: 321, Sigo la trad. de J.M." Ripalda en su ed. de la [llamada] Filosofía real, Madrid, 1984, p. 326.

30. Ibid.

31. Rechtsphil., $\$ 198$.

32. Parte 2.", título 8., 51 del ALR (en Anhang de Rechtsphil., ed. cit., p. 544).

33. Rechtsphil., $\$ 205$.

34. Cf. G. Pavanini, Hegel, la politica e la storia, Bari, 1980, pp, 149-150.

35. Vorlesungen aber Rechtsphilosophie, 1818 1831 (ed. K.H. Ilting), Stuttgart / Bad Camstatt, 1973. Nachschrift Homeyer: 1, 333.

36. Uber Einrichtunglandstandischer Verfassungen in den preussischen Staaten, en Werke, IV, 435 .

37. R. Kosellek, Preussen zwischen Reform und Revolution..., Stuttgart, 1967, pp. 338 y ss.

38. CF. La contstituctón en Alentania (trad de A. Negro), Madrid, 1972, p. 153.

39. Cf. [Beurtellung der] Verhanditugen in der Versanmitung der Landstände des Königsrechs Warttenberg int Jahr 1815 und 1816 , en $W_{4}$, 476-7.

40. Rechtsphil. $\$ 255$.

41. Systementwiurfe, III, en GW., 8: 281; Filosofia real (ed. Ripalda), p. 228.

42. P. Calderón de la Barca; La vide es suerto, Madrid, Hartzenbusch, 1881, p. 86, jomada segunda. 